Mémoires affrontées, Protestants et catholiques face à la Révolution dans les montagnes du Languedoc

Philippe Goujard

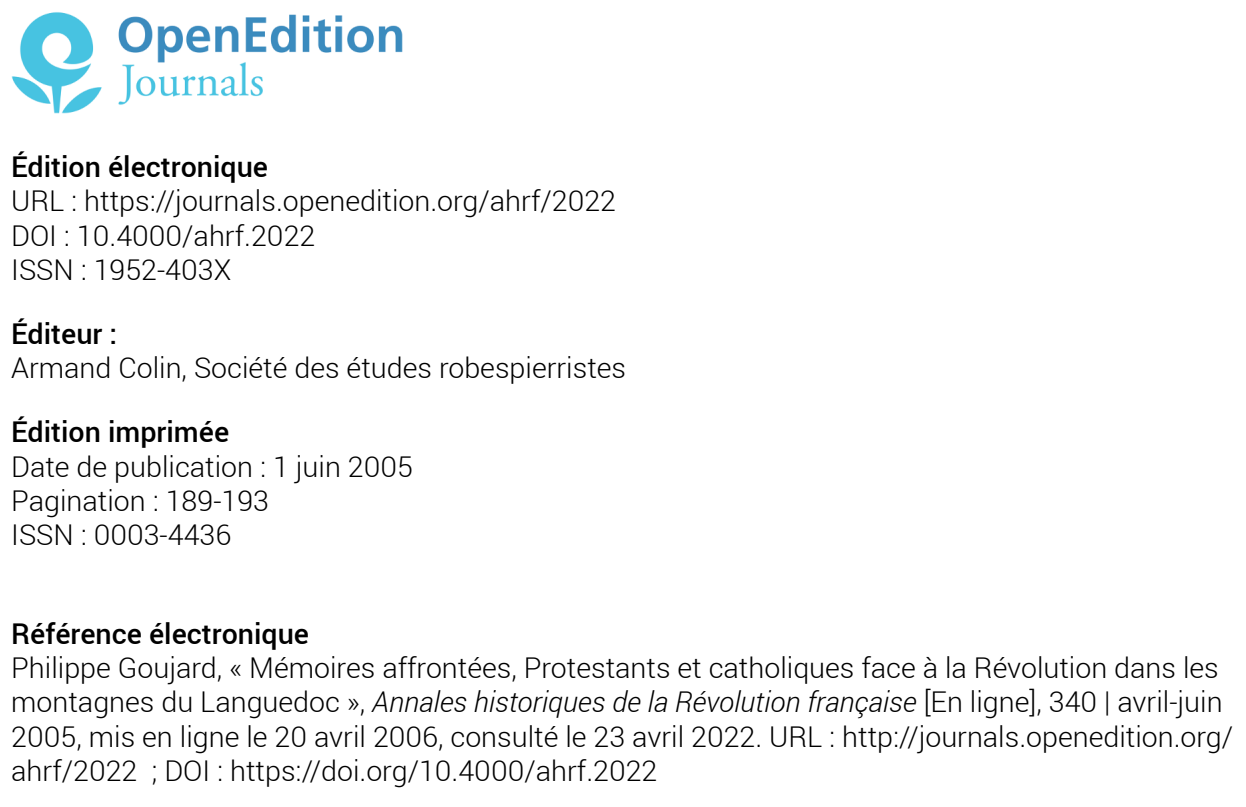

Ce document a été généré automatiquement le 23 avril 2022.

Tous droits réservés 


\title{
Mémoires affrontées, Protestants et catholiques face à la Révolution dans les montagnes du Languedoc
}

\author{
Philippe Goujard
}

\section{RÉFÉRENCE}

Valérie SOTTOCASA, Mémoires affrontées, Protestants et catholiques face à la Révolution dans les montagnes du Languedoc, Rennes, Presses Universitaires de Rennes, 2004, 416 p., ISBN 2-86847-964-2, 21 e.

1 C'est un bien beau travail, et de belle écriture, que nous offre Valérie Sottocasa. Son ambition a été de saisir les ressorts de la Révolution et de la Contre-Révolution dans les montagnes du Midi languedocien, longtemps considérées comme des isolats passifs demeurés à l'écart de la Révolution. Le pari a été tenu grâce à l'étude de 850 émeutes dans les hautes régions de cinq départements du Midi languedocien.

2 La première partie - six chapitres - s'ouvre par la peinture de l'année 1789. Les montagnes des Cévennes, du Rouergue et du Gévaudan s'engagent dans le mouvement révolutionnaire avec autant d'ardeur que les plaines. Les difficultés économiques de 1789 provoquent des troubles qui secouent la montagne. La Grande Peur touche les communes protestantes des Cévennes, mais épargne les Causses, l'Aubrac et la Margeride catholiques. En effet, les protestants ont tout à craindre d'une réaction catholique, eux qui viennent d'envoyer une majorité patriote à l'Assemblée où le pasteur Rabaud Saint-Étienne devient vite une figure éminente du parti patriote. Dès les tout débuts de la Révolution, la différence confessionnelle imprègne donc celle des comportements.

3 Mais le choc décisif est la question religieuse : elle brise dès 1790, avec le débat national sur la motion de Dom Gerle, le consensus entre catholiques et protestants, réel à l'annonce de la convocation des États généraux. Le conflit violent entre patriotes et 
royalistes est plus précoce qu'ailleurs. La «bagarre de Nîmes » en juin 1790 dit la peur des catholiques devant la perspective d'un retour aux affaires d'une élite protestante riche et cultivée.

4 La Constitution civile du clergé massivement refusée par les curés, dans la Lozère plus que dans le Gard, mobilise immédiatement les catholiques qui, dès janvier 1791, se soulèvent à Millau, avec le soutien du maire, de Bonald, qui dirige un club composé d'aristocrates, mais aussi de représentants des classes moyennes, des artisans et des paysans. L'agitation s'étend aux campagnes rouergates et aux Cévennes catholiques. Partout les prêtres constitutionnels sont vilipendés, empêchés dans leurs fonctions, quand ils ne sont pas chassés. Les Cévennes font exception: il est vrai que dans les communes protestantes la population est assez indifférente à la question du serment que les curés ont au reste massivement prêté.

5 L'auteur individualise trois régions : les pays " homogènes ", soit très favorables à la Révolution comme les Cévennes protestantes, soit violemment hostiles comme la Lozère, les pays où le rejet de la Constitution civile du clergé ne conduit pas à un ralliement à la Contre-Révolution comme l'Aubrac et la Grande Causse, et les pays "apolitiques", du moins en apparence, car la Constitution civile du clergé y est ignorée : les prêtres réfractaires continuent leur fonction dans un calme tel que les autorités feignent d'ignorer cette situation : c'est le cas de la Margeride.

6 Très tôt aussi, la Contre-Révolution organise ses réseaux, en liaison avec l'émigration : parmi les plus actifs, celui de l'abbé Sohier, prieur de Cotignac. Ils préparent une insurrection, sûrs de l'appui des masses populaires catholiques, très précocement engagées dans la dynamique contre-révolutionnaire. L'échec, en février 1792, du soulèvement de Mende - la «bagarre de Mende » - n'entame pas la confiance des chefs contre -révolutionnaires. La Contre-Révolution a son programme, la défense du catholicisme traditionnel, ses bastions, Millau, Mende, ses zones de repli, le haut pays, son organisation et sa base de masse. Mais si le monde paysan catholique est unanime à défendre les prêtres réfractaires, il se méfie encore des aristocrates avec lesquels il était en conflit quelques années plus tôt. Aussi les chefs royalistes ont-ils l'intelligence de mettre au premier plan la question religieuse, seule capable de rassembler les masses catholiques, contribuant ainsi à accentuer le fondement confessionnel de l'engagement politique des deux partis.

7 La levée d'hommes de 1793 fournit les fantassins de la Contre-Révolution. Le refus est notoire, avec un taux d'insoumission de 50 à $60 \%$, à l'exception sans surprise des Cévennes protestantes. Des régions, comme les confins de l'Hérault, qui avaient accepté la Constitution civile du clergé et où le clergé avait majoritairement juré, basculent dans la Contre-Révolution. L'appel au soldat est ponctué d'insurrections locales. 4000 insoumis se réfugient dans les montagnes et forment les troupes de l'insurrection de Charrier en mai 1792. Elle parvient à prendre Mende avant d'être anéantie par l'armée. Charrier et trente-neuf de ses partisans sont guillotinés en 1793.

8 Face au péril royaliste, les patriotes ne sont restés ni inertes ni inactifs. Impuissants à briser la résistance religieuse, ils placent le combat sur le terrain social. En décembre 1791 et plus encore en avril 1792, les paysans patriotes, soutenus plus ou moins discrètement par les élus et les membres des clubs, s'attaquent aux vestiges de la féodalité : c'est la "guerre des châteaux ». En 1791, les cibles sont symboliques : tours, girouettes, armoiries sont détruites. Fait notable : aucune atteinte à la propriété ni aux personnes n'est commise et même les papiers terriers ont échappé au feu. Le 
mouvement revêt dans les Cévennes, épicentre de l'agitation, un caractère politique autant que social : il s'agit de briser la force politique de l'aristocratie royaliste. De là, la violence accrue des insurgés : en 1791, on avait démoli les tours et les girouettes, en avril 1792 on attaque plus de cinquante châteaux dans le département du Gard. La politisation du mouvement est accentuée par la participation plus active des membres des clubs. L'insurrection est le fait exclusif des protestants, dans le Gard, la Lozère et dans l'Hérault. La "guerre des châteaux » est la réponse politique aux insurrections royalistes des catholiques.

9 Apparaît à la fin de 1791 une autre forme d'action qui culmine après la fin du mouvement anti-féodal. Les attroupements cessent et font place aux actions de bandes composées de volontaires en garnison et dirigées par des fils de familles protestantes aisées comme la «Bande noire» de Saint-Affrique, la plus redoutable. Prétendant, comme les participants aux attaques de châteaux, exercer la justice révolutionnaire que les autorités semblent incapables de mettre en place, ces bandes, ne comptant jamais plus d'une quarantaine de membres, s'attaquent physiquement aux nobles, aux prêtres réfractaires et à tous les suspects d'aristocratisme. Le moment de leur action - la nuit -, leurs costumes - manteaux et chapeaux noirs, masques - font vivre les catholiques dans un état d'insécurité permanente accrue par la circulation de rumeurs qui enflent leur nombre et font croire à leur ubiquité.

10 La montagne ne s'est donc pas montrée moins émeutière que la plaine. Et, dans le cadre d'une mobilisation précoce des deux partis, chaque étape du processus de politisation a vu s'affirmer l'identité religieuse comme élément principal des différenciations politiques.

11 En un paradoxe qui n'est qu'apparent, la Terreur est le moment d'un affaiblissement du parti patriote. Les élites protestantes rallient le fédéralisme auquel s'opposent les artisans protestants qui réclament aussi contre leurs coreligionnaires aisés une politique économique dirigiste. Cette attitude du populaire contribue à l'échec de l'insurrection fédéraliste avant de faire place à une certaine passivité. La déchristianisation n'a guère d'impact, hors les abdications forcées de prêtres et de pasteurs et des gestes iconoclastes, mais la plupart sont le fait de l'armée avec le seul soutien des anciens des bandes patriotes : ce sont les hommes du général Lamarque qui, avec les membres de la bande noire de Saint-Affrique, devenus élus locaux, saccagent la cathédrale de Vabres, ancienne capitale d'un diocèse supprimé.

12 Mais la Terreur a aussi contraint à la réserve les royalistes. Réserve dont ils sortent dès la chute de Robespierre. Ils profitent de l'affaiblissement du parti patriote, diminué par les épurations successives et la crise économique, conséquence du retour au libéralisme économique qui décourage le petit peuple protestant, sauf dans les Cévennes qui demeurent un îlot jacobin. 1795 voit éclater une terreur blanche et la violence redouble lors des élections de l'an V. Ses cibles? Les patriotes et les acquéreurs de biens nationaux. À partir de 1796, la violence royaliste est endémique. Par rapport aux mouvements de 1791, seules ont changé les formes de la violence, reproduisant celles adoptées par le parti patriote après la guerre des châteaux : plus d'attroupements, mais des raids menés par des groupes, en nombre aussi réduit que celui des bandes patriotes de 1792, contre les partisans de la Révolution et les acheteurs de biens nationaux. La plus connue est celle de l'insaisissable abbé Soyer, entré en clandestinité dès 1791, et qui, à plus de 60 ans, mène la vie rude du maquisard, passant de grotte en grotte. Ces groupes, qui jouissent de la complicité des populations catholiques par conviction, mais 
aussi par peur des représailles, et dont les rumeurs amplifient l'efficacité, comme dans le cas des bandes patriotes, sont particulièrement actifs dans les régions de Lodève et de Castres. Il faudra le Concordat pour rétablir la paix.

13 La seconde partie, interprétative, - 4 chapitres - commence par une description du milieu montagnard. Milieu naturellement hostile où domine, surtout en Gévaudan, une micro-propriété paysanne insuffisante pour assurer l'auto-subsistance. De là l'importance des biens communaux et de l'artisanat, indispensables compléments de ressources. En ces terres de misère, les Cévennes font figure d'îlot de prospérité grâce à l'essor de l'élevage des vers à soie.

14 Il y a la montagne réelle, il y a la montagne vue par les élites. Leur conviction de l'ignorance des paysans, prouvée par l'analphabétisme et le maintien du patois, les conduit à une attitude contradictoire. D'une part, les élites voient dans l'« arriération » culturelle des rustres le motif de leur opposition à la Révolution. Comment expliquer autrement leur refus de transformations qui ne peuvent que leur apporter le bonheur? Aux yeux des dirigeants révolutionnaires, cette ignorance explique la facilité qu'ont les chefs contre-révolutionnaires à manipuler un peuple demeuré dans l'enfance. Mais, d'autre part, ce peuple grossier est aussi considéré comme sauvage et menaçant. Les montagnes sont des sites d'insoumission qu'il faut constamment surveiller et éventuellement châtier.

Retournant à la réalité, l'auteur met en lumière l'influence des solidarités familiales et communautaires dans les choix politiques. Elle souligne le rôle majeur de deux groupes, les femmes et les jeunes. Les femmes sont au premier rang des émeutes de subsistances et du combat pour la défense des réfractaires et le rejet des constitutionnels. Elles sont même majoritaires dans $6 \%$ des émotions contre-révolutionnaires. Mais la politisation croissante de l'agitation royaliste et ses formes nouvelles les écartent du mouvement: les femmes n'ont pas plus leur place dans les bandes qu'elles n'ont leur place dans les clubs. Quant aux jeunes, c'est la sinistre perspective d'un départ pour le front qui les fait agir : ils sont $21 \%$ dans les émeutes suscitées par le refus de l'enrôlement forcé dans l'armée. À la différence des femmes, l'action en bandes amplifie leur rôle.

16 Bien évidemment, c'est la question religieuse qui est fondamentale. Le refus de la Constitution civile du clergé tient d'abord au taux d'encadrement du clérical: il est d'autant plus massif que le clergé est nombreux. Joue plus encore l'origine sociale des prêtres, issus à $66 \%$ de la paysannerie, ce qui distingue la région du reste de la France. Ils desservent souvent les paroisses où ils sont nés. Cet enracinement les a conduits à s'accommoder d'une religiosité traditionnelle restée attachée à des gestes et des observances jugés peu orthodoxes par la Réforme catholique. Ainsi s'explique la solidarité étroite des fidèles à leur égard. Et la vigueur inentamée de cette religiosité populaire explique aussi le refus agressif de toute réforme religieuse d'autant plus que les réfractaires ont convaincu sans trop de peine les fidèles que la Constituante voulait réorganiser l'Église catholique sur le modèle protestant, faisant ainsi œuvre diabolique. Or, le protestant est l'Ennemi.

Le chapitre 9 contient sans doute les pages les plus intéressantes et les plus originales du livre. Il décrit la mémoire des deux communautés telle qu'elle était en 1790. Le souvenir des guerres confessionnelles depuis 1560 a structuré une mémoire protestante. Dans ce processus, plus que les guerres de Religion, c'est l'insurrection de Rohan (1620-1629) qui a été déterminante. C'est alors que les Cévennes ont gagné leur réputation de bastion inexpugnable de la Réforme et que les Cévenols ont conquis le 
titre de champions de la foi et de successeurs de David, Josué et de Juda Maccabée. La défaite de Rohan n'a en rien entamé leur combativité que traduit une résistance parfois violente aux efforts de conversion menés au XVIIe siècle. Missionnaires et secondairement curés sont parfois molestés et les symboles de la volonté de reconquête catholique, comme les croix plantées à la fin des missions, sont détruits. La guerre des Camisards a renforcé la fierté de gens qui n'ont plié qu'un court moment, au lendemain de la révocation de l'édit de Nantes. Les patriotes se voient avant tout comme les fils de ces premiers combattants de la liberté et inscrivent leur combat révolutionnaire dans le droit fil de celui de leurs ancêtres.

18 La mémoire catholique des conflits religieux n'est pas moins vivace, mais nourrit, à la différence de la protestante, l'hostilité à la Révolution. Elle est structurée par la peur de gens qui se savent minoritaires et en position d'infériorité sociale par rapport aux protestants. Cette angoisse est avivée par le souvenir des massacres de catholiques par les protestants pendant les guerres de Religion et des Camisards. Elle explique leur attachement à l'autorité royale, seule garante de leur survie. En brisant l'alliance du trône et de l'autel, la Révolution semble ôter toute protection, en particulier aux classes moyennes qui ne doivent leurs positions de pouvoir qu'au soutien de la royauté et risquent d'être éliminées par les élites protestantes. Voilà pourquoi la lutte pour le contrôle de la municipalité de Nîmes en 1790, simple compétition électorale comme en connaissent alors presque toutes les villes du royaume, dégénère en massacre.

La Révolution réveille les deux mémoires, assoupies par la période d'apaisement du conflit religieux au temps des Lumières. Or la mémoire donne une grille de lecture aux événements révolutionnaires. Pour les catholiques, la «bagarre de Nîmes" est la répétition de la Michelade de 1567, l'action des bandes noires réédite les raids camisards. Pour les protestants, les contre-révolutionnaires sont les fils des massacreurs catholiques des temps jadis. Sans cet affrontement des deux mémoires, entretenues par les dirigeants des deux camps, on ne saurait comprendre que la division religieuse ait été la dimension essentielle de la rupture révolutionnaire dans la région, rejetant au second plan le rôle des clivages sociaux, mais sans les faire disparaître.

Précocité et violence des combats, rôle décisif des oppositions confessionnelles auxquelles la Révolution a donné un contenu politique, à tel point que le parti patriote finit par se confondre avec la communauté protestante et le parti royaliste avec la communauté catholique, font donc l'originalité d'un Midi languedocien, brillamment revisité par Valérie Sottocasa, dans l'espace français révolutionnaire et révolutionné. 